\title{
Heavy lithium-doped ZnO thin films prepared by spray pyrolysis method
}

\author{
M ARDYANIAN* and N SEDIGH \\ School of Physics and Centre for Solid State Physics Research, Damghan University, 3671641167, Damghan, Iran
}

MS received 21 July 2013; revised 5 August 2013

\begin{abstract}
Lithium-doped $\mathrm{ZnO}$ thin films $\left(\mathrm{ZnO}: \mathrm{Li}_{x}\right)$ were prepared by spray pyrolysis method on the glass substrates for $x(x=[\mathrm{Li}] /[\mathrm{Zn}])$ value varied between 5 and $70 \%$. Structural, electrical and optical properties of the samples were studied by X-ray diffraction (XRD), UV-Vis-NIR spectroscopy, scanning electron microscopy (SEM), Hall effect and sheet resistance measurements. XRD results show that for $x \leq 50 \%$, the structure of the films tends to be polycrystals of wurtzite structure with preferred direction along ( 002$)$. The best crystalline order is found at $x=20 \%$ and the crystal structure is stable until $x=60 \%$. The Hall effect results describe that $\mathrm{Li}$ doping leads to change in the conduction type from $n$ - to $p$-type, again it changes to $n$-type at $x=70 \%$ and is attributed to self-compensation effect. Moreover, the carrier density was calculated in the order of $10^{13} \mathrm{~cm}^{-3}$. The resistivity of Li-doped films decreases until $22 \Omega \mathrm{cm}$ at $x=50 \%$. Optical bandgap was reduced slightly, from 3.27 to $3.24 \mathrm{eV}$ as a function of the grain size. Optical transmittance in the visible range reaches $T=97 \%$, by increasing of $\mathrm{Li}$ content until $x=20 \%$. Electrical and optical properties are coherent with structural results.
\end{abstract}

Keywords. ZnO; spray pyrolysis; lithium; XRD; UV-Vis-NIR.

\section{Introduction}

Zinc oxide $(\mathrm{ZnO})$ is a semiconductor with a wide and direct bandgap equal to $3.37 \mathrm{eV}$ at $300 \mathrm{~K}$, large exciton binding energy $(60 \mathrm{meV})$ and strong luminescence emission in ultraviolet (UV) domain. It has become the second most widely studied material after Si for the past decade, because of its advantages as low material cost, low resistivity, high transparency in the visible range, relatively low deposition temperature and stability in hydrogen plasma (Özgür et al 2005). It is presently used in many diverse products, such as piezoelectric transducers, varistors, transparent conducting layers for the photovoltaic industry, optoelectronic application (Soki et al 2000; Look et al 2004), as well as application in heterostructures for fabrication of photodiodes (Jeong et al 2003), diluted magnetic semiconductors (Ando et al 2001) and nanopiezotronics (Chen et al 2010). $\mathrm{ZnO}$ is naturally n-type semiconductor because of a deviation from stoichiometry, due to the presence of intrinsic defects such as oxygen vacancies and $\mathrm{Zn}$ interstitials (Özgür et al 2005). For fabricating the light-emitting diodes, $p-n$ junction is needed; known acceptors in $\mathrm{ZnO}$ include group-I elements such as lithium (Li) (Bilgin 2009) $\mathrm{Na}$ and $\mathrm{K}$, copper (Cu) (Kanai 1991a), silver (Ag), (Kanai 1991b), and group-V elements such as N, P and As. However, the

\footnotetext{
*Author for correspondence (ardyanian@du.ac.ir)
}

formation of deep acceptor levels, implies not to contribute significantly to $p$-type conduction. It has been believed that the most promising dopants for $p$-type $\mathrm{ZnO}$ are the group- $\mathrm{V}$ elements, although theory suggests some difficulty in achieving shallow acceptor level. $\mathrm{ZnO}$ films have been prepared by different techniques, including spray pyrolysis, sputtering, epitaxy, sol-gel, chemical vapour deposition, molecular beam and evaporation (Gal et al 2000; Studenikin et al 2000). Among these techniques, spray pyrolysis is a simple and inexpensive method for the preparation $\mathrm{ZnO}$ films. In this article, $\mathrm{Li}$ doping in a wide range of dopant content was effectuated and its influence on the electrical, structural and optical properties of $\mathrm{ZnO}$ thin films investigated.

\section{Experimental}

Lithium-doped $\mathrm{ZnO}\left(\mathrm{ZnO}: \mathrm{Li}_{x}\right)$ thin films were prepared by spray pyrolysis techniques on glass substrates. Before deposition, the substrates were cleaned with normal detergent and deionized distilled water, later they were rinsed with 2-propanol. The spraying set-up consists of a scanning spraying nozzle placed $35 \mathrm{~cm}$ apart from the heated substrates with the flow rate of $3 \mathrm{~mL} / \mathrm{min}$. The carrier gas was dry air at 3 atmospheres pressure. The substrates were installed on a hot plate rotating at $5 \mathrm{rpm}$ rate. The initial spraying solution was $0.15 \mathrm{~mol} / \mathrm{L}$ of zinc acetate $\left(\mathrm{Zn}\left(\mathrm{CH}_{3} \mathrm{COO}\right)_{2} \cdot 2 \mathrm{H}_{2} \mathrm{O}\right)$ in $100 \mathrm{~mL}$ solution of water and 
2-propanol with 1:3 ratio as a solvent. The best spray parameters were determined based on a systematic study as $3 \mathrm{~mL} / \mathrm{min}$ for deposition rate, $450{ }^{\circ} \mathrm{C}$ for substrate temperature and $100 \mathrm{~mL}$ for solution volume.

$\mathrm{Li}$ doping was done by adding lithium chloride in zinc acetate solution, $\mathrm{Li}$ concentration was calculated as; $x=[\mathrm{Li}] /[\mathrm{Zn}]=[\mathrm{LiCl}] /\left[\mathrm{Zn}\left(\mathrm{CH}_{3} \mathrm{COO}\right)_{2}\right]$ and its values were chosen between 5 and $70 \%$.

The average thickness of the thin films was around $130 \mathrm{~nm}$, measured utilizing UV-Vis-NIR spectroscopy data and calculating by PUMA software (Birgin et al $1999)$. The sheet resistance $\left(R_{\mathrm{s}}\right)$ of the films was measured by two-point probe method using thermally evaporated aluminum electrodes; the resistivity was calculated using the sheet resistance by the following relation

$$
\rho=R_{\mathrm{s}} t
$$

Conduction type ( $n$ or $p$ ) was determined by the Hall effect experiment using a coil of 100 turns for creating the magnetic flux density $(B)$ up to $150 \mathrm{mT}$, the power supply for creating the longitudinal voltage up to $15 \mathrm{~V}$. The measurement of the Hall voltage $\left(V_{\mathrm{H}}\right)$ was done by a microvoltmeter. Also, carriers' density was calculated using the Hall effect results and the following equation (Bagheri-Mohagheghi et al 2009)

$$
N_{n, p}=\frac{I B}{|q| V_{\mathrm{H}} t}
$$

where $I, t$ and $q$ are the measured current, the thickness of the films, electron charge, respectively. For the structural studies of the films, XRD patterns of $\mathrm{ZnO}$ and $\mathrm{ZnO}: \mathrm{Li}_{x}$ thin films were recorded by D8 Advance Bruker system using $\operatorname{CuK} \alpha(\lambda=0.15406 \mathrm{~nm})$ radiation. The average crystallite size, $D$, was calculated using the Scherrer's formula (Bagheri-Mohagheghi et al 2008)

$$
D=\frac{k \lambda}{\beta \cos \theta}
$$

where $\beta$ is the full-width at half-maximum (FWHM) of the corresponding XRD peak at radiant, $k$ is correction factor $(\approx 0.9)$ which is correlated to the shape of nanocrystals, considering the spherical shape. $\lambda$ is X-ray wavelength $\left(\lambda_{\mathrm{Cuk} \alpha}=0.15406 \mathrm{~nm}\right)$ and $\theta$ the Bragg diffraction angle. Surface morphology of the films was observed by Philips XL-30 SEM system. The optical measurements were carried out in the range of 190$1100 \mathrm{~nm}$ using Unico 4802 spectrophotometer system. The direct bandgap $\left(E_{\mathrm{g}}\right)$ of the prepared films was obtained from the extrapolation of the linear part of the $(\alpha h v)^{2}$ curve vs photon energy $(h v)$ and using the Tauc equation (Bagheri-Mohagheghi et al 2008)

$$
(\alpha h v)^{2}=A\left(h v-E_{\mathrm{g}}\right),
$$

where $\alpha$ and $E_{\mathrm{g}}$ are the absorption coefficient and the bandgap energy, respectively, and $A$ is a constant.

\section{Results and discussion}

\subsection{Structural properties}

3.1a XRD results: According to the procedure described in the previous section, figure 1 represents XRD patterns of $\mathrm{ZnO}: \mathrm{Li}_{x}$ thin films as a function of $\mathrm{Li}$ concentration. As illustrated, the spectra describe the wurtzite polycrystal structure with preferred orientation along $\left(\begin{array}{lll}0 & 0 & 2\end{array}\right)$. Diffraction peak angle of $\left(\begin{array}{llll}0 & 0 & 2\end{array}\right)$ planes for $\mathrm{ZnO}$ bulk single crystal is $34.42^{\circ}$ (JCPDS 0361451 and 40831); this peak lies at $34.57^{\circ}$ for undoped $\mathrm{ZnO}$ film of our samples. This shift to higher angles could be attributed to residual stress in $\mathrm{ZnO}$ thin films which causes the decrease in the inter-planar distance of the lattice.

By increasing the Li content $(x)$, a variation on the diffraction peak angle of $\left(\begin{array}{lll}0 & 0 & 2\end{array}\right)$ planes is observed; the peak centre shifts to lower and higher angles alternatively as a function of $x$ (table 1). This implies a competition between tensile and compressive stress in the lattice that

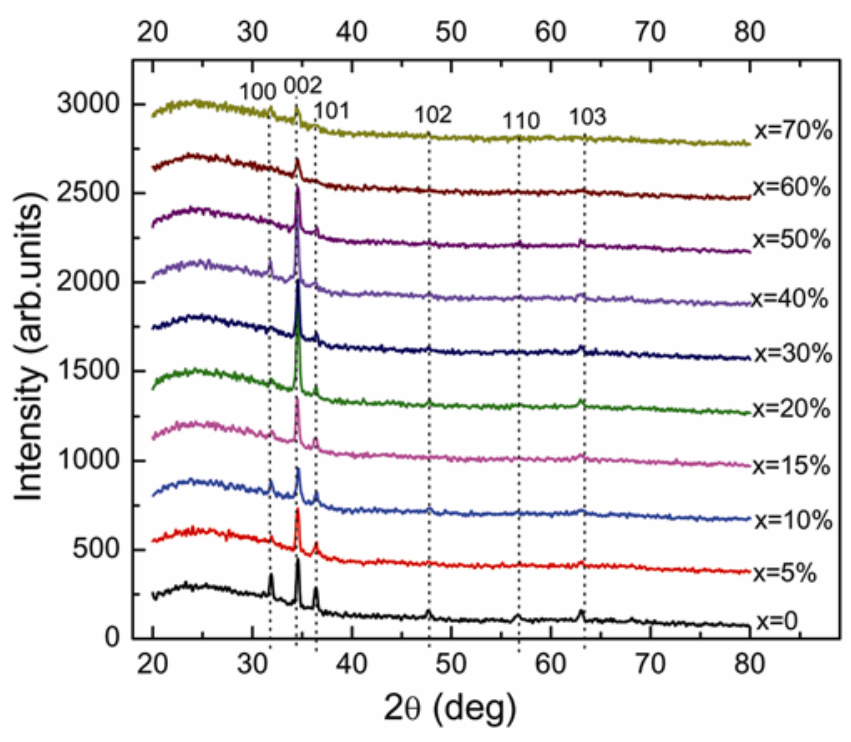

Figure 1. XRD pattern of $\mathrm{ZnO}: \mathrm{Li}_{x}$ thin film as a function of

\begin{tabular}{|c|c|c|c|c|}
\hline $\begin{array}{l}\text { Li content } \\
(x \text { at } \%)\end{array}$ & $2 \theta\left(^{\circ}\right)$ & $\begin{array}{c}\text { Interplanar } \\
\text { distance }(\AA)\end{array}$ & FWHM $\left(^{\circ}\right)$ & $\begin{array}{l}\text { Mean grain } \\
\text { size }(\mathrm{nm})\end{array}$ \\
\hline 0 & 34.59 & $2 \cdot 591$ & $0 \cdot 280$ & $29 \cdot 72$ \\
\hline 5 & 34.55 & $2 \cdot 594$ & $0 \cdot 298$ & 27.92 \\
\hline 10 & 34.60 & 2.591 & 0.279 & $29 \cdot 80$ \\
\hline 15 & 34.49 & $2 \cdot 598$ & 0.287 & $29 \cdot 00$ \\
\hline 20 & 34.55 & 2.594 & 0.267 & $31 \cdot 17$ \\
\hline 30 & 34.59 & 2.591 & $0 \cdot 248$ & $33 \cdot 56$ \\
\hline 40 & 34.50 & 2.601 & 0.260 & $32 \cdot 01$ \\
\hline 50 & 34.58 & 2.592 & 0.276 & $30 \cdot 13$ \\
\hline 60 & $34 \cdot 50$ & $2 \cdot 597$ & $0 \cdot 380$ & 21.90 \\
\hline
\end{tabular}
Li concentration.

Table 1. XRD parameters of $\mathrm{ZnO}: \mathrm{Li}_{x}$ thin films for different Li concentration. 
may be caused by substitution of Li atoms at the interstitial and $\mathrm{Zn}$ sites, respectively (Zeng et al 2005; Bilgin 2009). A decrease of FWHM and variation of the intensity of the $\left(\begin{array}{lll}0 & 0 & 2\end{array}\right)$ peaks, in comparison with undoped $\mathrm{ZnO}$ films, are observed for $x \geq 20 \%$ and $x<50 \%$, respectively. Increase of $\left(\begin{array}{lll}0 & 0 & 2\end{array}\right)$ peak intensity (table 1$)$ could be attributed to improve the crystallinity due to decreasing number of defects and increasing crystallites size; it could also be due to modification of nanocrystal growing process as a catalyser (Chu et al 2010). Decrease in the peak intensity is attributed to substitution of $\mathrm{Li}^{+}$ions with ionic radius $=0.68 \AA$ to $\mathrm{Zn}^{2+}$ ions with ionic radius $=$ $0.74 \AA$ as reported by other researchers (Bilgin 2009). For $50 \% \leq x \leq 70 \%$, the intensity of the $(002)$ peak decreases and the other diffraction peaks almost disappear. This is attributed to incorporation of more Li atoms that causes the increase in the density of more Li atoms in the interstitial sites; hence, the insoluble $\mathrm{Li}$ atoms are segregated at the grain boundaries and they suppress the growth of $\mathrm{ZnO}: \mathrm{Li}_{x}$ crystals (Nayak et al 2009). It is noted that the crystal structure of $\mathrm{ZnO}: \mathrm{Li}_{x}$ thin films is stable up to $\mathrm{Li}$ content of $70 \%$, which may be an advantage for the thin films prepared by spray pyrolysis method.

3.1b SEM images: The images of scanning electron microscopy (SEM) are represented in figure 2. An evolution in the morphology of the surfaces is observed as a function of $\mathrm{Li}$ content. The graining was modified for $x$ up to $20 \%$ and the grains are well separated. At $x=40 \%$ the large clusters were formed on the surface which has taken place by nucleation and coalescence of the grains at high $\mathrm{Li}$ content. It is assured that $\mathrm{Li}$ doping in $\mathrm{ZnO}$ influences nucleation density that both nucleation sites and the number of nuclei increase with increasing Li ion (Mohamed et al 2005; Lin et al 2007). It is confirmed in the figure $2(\mathrm{e}$ and $\mathrm{f}$ ) corresponding to $x=50$ and $60 \%$ in which the grains are well coalesced. For $x=70 \%$ (figure $2 \mathrm{~g}$ ), the sample is almost amorphous with a uniform and continuous surface. This is in coherence with XRD results and could be due to increase in the density of $\mathrm{Li}$ atoms in interstitial sites, which leads to segregate the insoluble $\mathrm{Li}$ atoms at the grain boundaries and suppress the growth of $\mathrm{ZnO}: \mathrm{Li}_{x}$ crystals (Nayak et al 2009).

\subsection{Optical properties}

3.2a Transmittance: Figure 3 shows transmittance of $\mathrm{ZnO}: \mathrm{Li}_{x}$ thin films vs wavelength and in different $\mathrm{Li}$ contents, $x$. As illustrated, for $10 \%<x \leq 20 \%$, transmittance of Li-doped films in the range of $400-550 \mathrm{~nm}$ increases by increasing the $\mathrm{Li}$ content and becomes greater than undoped $\mathrm{ZnO}$ films. This could be attributed to decrease in the number of defects and increasing the crystalline order after Li doping. For higher values of $x$, transparency slightly decreases, since most of the Li ions are located in interstitial sites of the atomic planes, the reduction of transparency could be attributed to dispersion of the visible light due to incorporation of $\mathrm{Li}$ atoms in the interstitial sites (Meyer et al 2007). Nevertheless, XRD results describe (figure 1), for $40 \% \leq x \leq 60 \%$, unless $\left(\begin{array}{lll}0 & 0 & 2\end{array}\right)$ diffraction peak, other peaks are almost suppressed, which could be a reason for decreasing light dispersion and increasing transparency in this range of Li content.

3.2b Bandgap energy: Optical bandgap of the thin films can be obtained by extrapolation of the curves based on (4). As illustrated in figure 4, all of the doped thin films generally represent a bandgap narrowing about $0.02 \mathrm{eV}$ compared with undoped $\mathrm{ZnO}$ thin film; this low reduction could be explained by the growth of the grain size, which are been in table 1 and observed in SEM images. For $x=5 \%$, in spite of reduction of grains size, a bandgap narrowing is observed; it could be attributed to the local electric fields due to impurity, disorder or any other defects which lead to affect the band tails near the band edge (Bilgin 2009). For $x>5 \%$, a bandgap widening is observed; The bandgap of $\mathrm{ZnO}$ is particularly sensitive to small changes in carrier concentration, grain boundary configuration and film stress as reported in the literature (Srikant and Clarke 1997, 1998). Also, the bandgap value of $\mathrm{ZnO}$ films generally increases with $\mathrm{Li}$ doping, which converts the shallow donor Zn sublevels to deep-sublevels below the conduction band (Sberveglieri et al 1992; Mohamed et al 2001) as represented in the inset of figure 4 for $x<50 \%$, another reason for increase of the bandgap could be the Burstein-Moss (B-M) effect (Bin et al 2009). While for heavy Li-doped thin films $(x>50 \%)$ there is an evident narrowing of the bandgap, which could be attributed to the combined effect of the conduction-band renormalization (Bin et al 2009).

\subsection{Electrical properties: Hall effect and sheet resistance}

Hall effect experiments were done for determining the conduction type of semiconductor and also the carrier density. Table 2 and figure 5 represent the results of Hall effect and sheet resistance measurements as a function of $x$. Li-doped samples are $p$-type semiconductors for $x \leq 60 \%$ and carrier density is found in the order of $10^{13} \mathrm{~cm}^{-3}$. At $x=70 \%, p$-type conduction changes to $n$-type again. Resistivity decreases continuously and reaches a minimum at $x=50 \%$, it increases at $x=60 \%$ and decreases again at $x=70 \%$. The generation of $p$-type $\mathrm{ZnO}$ film is due to substitution of acceptor Li ions for $\mathrm{Zn}$ ions (Zeng et al 2006). The maximum solubility of Li is estimated to be $10^{19} \mathrm{~cm}^{-3}$ under O-rich conditions (Lee and 

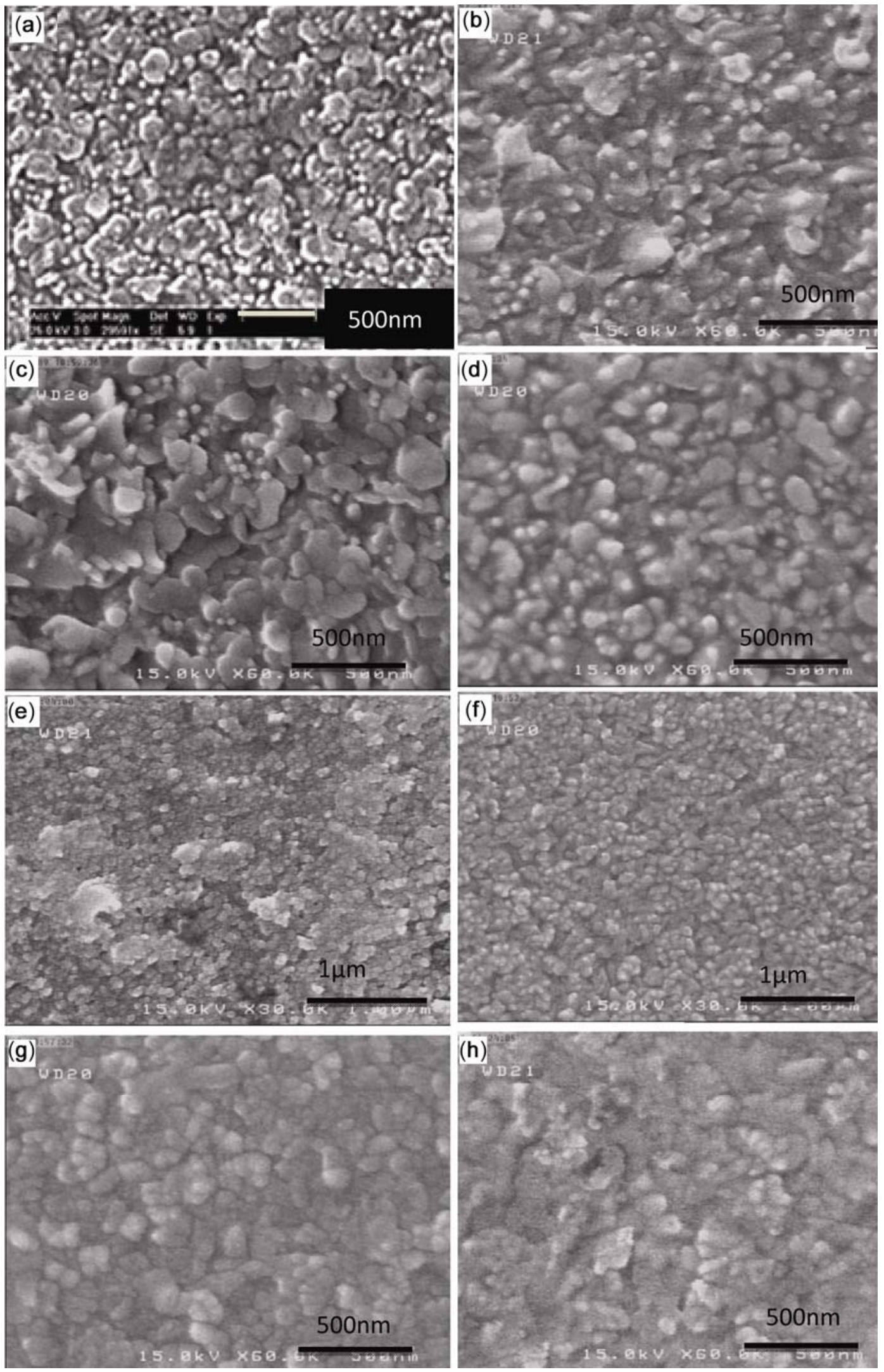

Figure 2. SEM images of $\mathrm{ZnO}: \mathrm{Li}_{x}$ thin films for different $\mathrm{Li}$ concentrations. (a) Undoped $\mathrm{ZnO}$, (b) $x=5 \%$, , (c) $x=10 \%$, (d) $x=20 \%$, (e) $x=40 \%$, (f) $x=50 \%$, (g) $x=60 \%$ and (h) $x=70 \%$. 


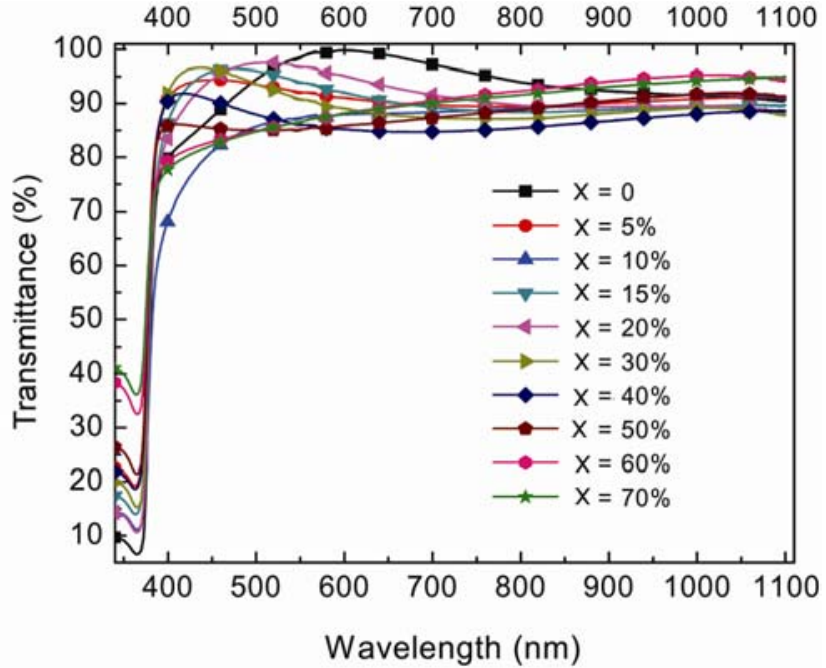

Figure 3. Transmittance curves of $\mathrm{ZnO}: \mathrm{Li}_{x}$ thin films as a function of lithium content $(x)$.

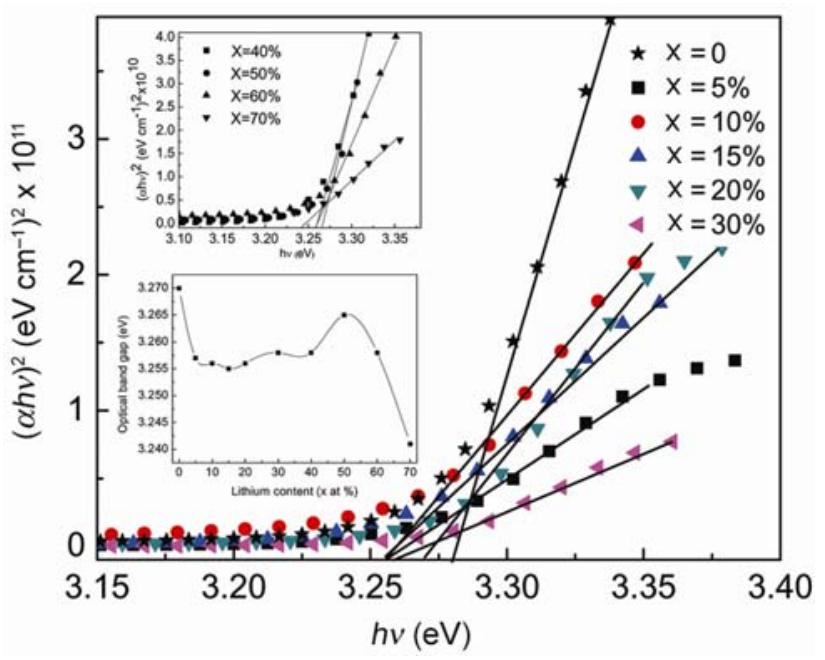

Figure 4. Optical bandgap of $\mathrm{ZnO}: \mathrm{Li}_{x}$ thin films as a function of lithium content $(x)$; down inset: Bandgap evolution vs Li content.

Table 2. The results of Hall effect and sheet resistance measurements as a function of $x$.

\begin{tabular}{lcccc}
\hline $\begin{array}{l}\text { Li content } \\
(x \text { at\% })\end{array}$ & $\begin{array}{c}\text { Semiconductor } \\
\text { type }\end{array}$ & $\begin{array}{c}\text { Carrier density } \\
\left(\mathrm{cm}^{-3}\right) \times 10^{13}\end{array}$ & $\begin{array}{c}\text { Sheet resistance } \\
(\mathrm{M} \Omega / \square)\end{array}$ & $\begin{array}{c}\text { Resistivity }(\rho) \\
(\Omega \mathrm{cm})\end{array}$ \\
\hline 0 & $n$ & $4 \cdot 28$ & $8 \cdot 1$ & 102 \\
5 & $p$ & 6 & 4 & 64 \\
10 & $p$ & $34 \cdot 2$ & $3 \cdot 3$ & 49 \\
15 & $p$ & 6 & 6 & 54 \\
20 & $p$ & $13 \cdot 2$ & $3 \cdot 8$ & 30 \\
40 & $p$ & $0 \cdot 3$ & $3 \cdot 9$ & 44 \\
50 & $p$ & 3 & 15 & 22 \\
60 & $p$ & 29 & 33 & 310 \\
70 & $n$ & $1 \cdot 4$ & 23 \\
\hline
\end{tabular}

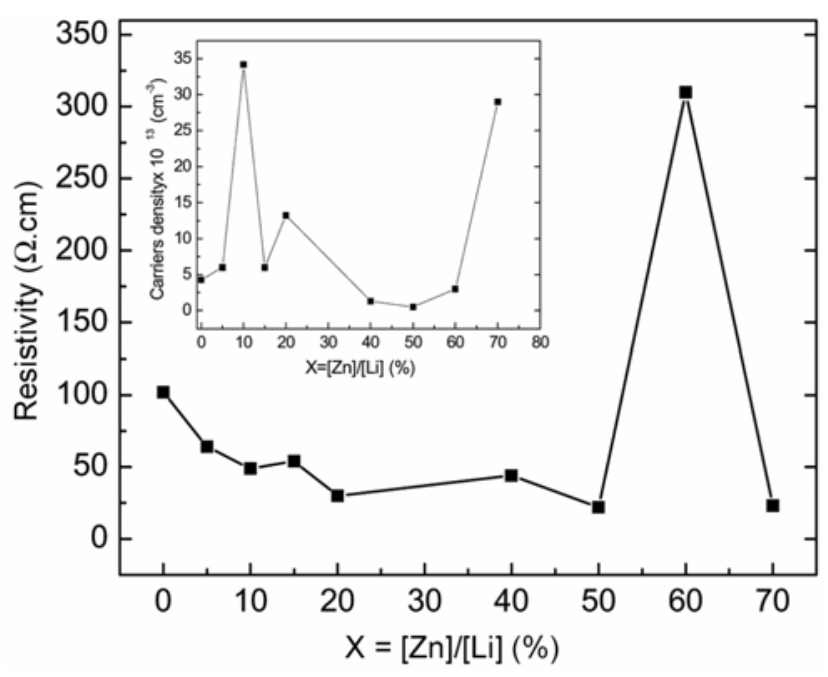

Figure 5. Resistivity and carrier density (inset) as a function of Li content.

Chang 2006), which corresponds to low values of $x$ in our samples. For higher values of $\mathrm{Li}$ content $(x=70 \%)$ excess of highly mobile Li ions incorporated in interstitial sites as donor defect (self-compensation effect) leads to change of conduction type to $n$ (Lander 1960; Lee and Chang 2006; Meyer et al 2007). As seen in table 2, the carriers density at $x=10 \%$ is more than $x=20 \%$, while resistivity at $x=10 \%$ is more than at $x=20 \%$. It is attributed to quality of the surface (figures $2 \mathrm{~b}$ and c); at $x=20 \%$ the grains are more coalesced and their sizes are uniform, while at $x=10 \%$ the grains are well separate with diverse sizes, which leads to the increase of carriers dispersion in the grains boundaries and resistivity as well. General decrease of the resistivity for $x<60 \%$ is attributed to increase in holes density; this leads to the suppression of intrinsic donor defects and modification of the crystalline structure as observed in XRD results (figure 1). Increase of resistivity for heavy doping $(x=60 \%)$ is attributed to carrier scattering by $\mathrm{Li}$ ions incorporated in interstitial sites and they play the role of donor defects. At $x=70 \%$, conduction type changes to $n$-type and carrier density increases (table 2) and resistivity decreases again (figure 5); regarding microscopy images (figure $2 \mathrm{e}$ ), at $x=70 \%$, grain boundaries are suppressed and the surface becomes uniform and continuous due to segregation of insoluble $\mathrm{Li}$ atoms at grain boundaries. This leads to suppression of 
electrons scattering in grain boundaries and the resistivity reduction.

\section{Conclusions}

In this work, the influence of Li doping on the structural, optical and electrical properties of $\mathrm{ZnO}$ thin films for a wide range of $\mathrm{Li}$ content was investigated. It is found that, up to $50 \%$ of $\mathrm{Li}$ content, the structure is wurtzite polycrystal with preferred orientation along $\left(\begin{array}{lll}0 & 0 & 2\end{array}\right)$. The crystal structure is stable for $x$ up to $70 \%$. A low bandgap narrowing was observed, which was attributed to growing of the grains. Carriers density and resistivity were measured and found in the order of $10^{13} \mathrm{~cm}^{-1}$ and about $40 \Omega \mathrm{cm}$, respectively, that resistivity generally decreases by $\mathrm{Li}$ doping. The samples have the best transmittance in the visible range for Li content up to $20 \%$. This is attributed to modification of the crystalline structure and suppression of the intrinsic defects. $\mathrm{ZnO}: \mathrm{Li}_{x}$ thin films have $p$-type conduction, which change to $n$-type at $x=70 \%$; this effect is attributed to self-compensation effect of lithium atoms, incorporated in interstitial sites of the lattice. As a result, $p$-type conduction, high transparency in the visible range, excellent crystal stability and low resistivity for doping up to $70 \%$ are the advantages of $\mathrm{ZnO}: \mathrm{Li}_{x}$ thin films prepared by spray pyrolysis method. Hence, it is a good substitution candidate for TCO materials and fabrication of $p-n$ junctions based on $\mathrm{ZnO}$.

\section{Acknowledgements}

This work was supported financially by the Research Council of Damghan University in I R Iran (Grant No. 7035). The authors also wish to acknowledge Dr M M Bagheri-Mohagheghi for technical and scientific support of this work.

\section{References}

Ando K, Saito H, Jin Z, Fukumura T, Kawasaki M, Matsumoto Y and Koinuma H 2001 J. Appl. Phys. 897284

Bagheri-Mohagheghi M M, Shahtahmasebi N, Alinejad M R, Youssefi A and Shokooh-Saremi M 2008 Phys. B: Condens. Matter 4032431
Bagheri-Mohagheghi M M, Shahtahmasebi N, Alinejad M R, Youssefi A and Shokooh-Saremi M 2009 Solid State Sci. 11233

Bin W, Yue Z, Jiahua M and Wenbin S 2009 Appl. Phys. A94 715

Birgin E G, Chambouleyron I and Martınez J M 1999 J. Comput. Phys. 151862

Bilgin V 2009 J. Electron. Mater. 381969

Chen Y Q, Zheng X J, Mao S X and Li W 2010 J. Appl. Phys. 107094302

Chu H, Wei L, Cui R, Wang J and Li Y 2010 Coordination Chem. Rev. 2541117

Gal D, Hodes G, Lincot D and Schock H W 2000 Thin Solid Films $\mathbf{3 6 1} 79$

Jeong I S, Kim J H and Im S 2003 Appl. Phys. Lett. 832946

Joint Committee on Powder Diffraction Standards, Powder Diffraction File, (Philadelphia, PA: ASTM, 1967). Card 0361451 (for $\mathrm{ZnO}$ hexagonal) and 40831 (for $\mathrm{Zn}$ hexagonal)

Kanai Y 1991a Jpn. J. Appl. Phys. 30703

Kanai Y 1991b Jpn. J. Appl. Phys. 302021

Lee E C and Chang K J 2006 Phys. B: Condens. Matter 376707

Lander J J 1960 J. Phys. Chem. Solids 15324

Lin W, Ma R, Shao W and Liu B 2007 Appl. Surf. Sci. 2535179

Look D C, Claflin B, Alivov Y I and Park S J 2004 Phys. Status Solidi (A) 2012203

Meyer B K, Stehr J, Hofstaetter A, Volbers N, Zeuner A and Sann J 2007 Appl. Phys. A88 119

Mohamed G A, Abd El-Moiz A B and Rashad M 2005 Phys. B: Condens. Matter 370158

Mohamed G A, Mohamed E M and Abu El-Fadl A 2001 Phys. B: Condens. Matter 308949

Nayak P K, Jang J, Lee C and Hong Y 2009 Appl. Phys. Lett. 95193503

Özgür U, Alivov Y I, Liu C, Teke A, Reshchikov M A, Dogan S and Morkoc H 2005 J. Appl. Phys. 98041301

Sberveglieri G Groppelli S, Nelli P, Quaranta F, Valentini A and Vasanelli L 1992 Sens. Actuators B: Chem. 7747

Soki T T, Hatanaka Y and Look D C 2000 Appl. Phys. Lett. 763257

Studenikin S A, Golego N and Cocivera M 2000 J. Appl. Phys. 872413

Srikant V and Clarke D R 1998 J. Appl. Phys. 835447

Srikant V and Clarke D R 1997 J. Mater. Res. 121425

Zeng Y J, Ye Z Z, Xu W Z, Chen L L, Li D Y, Zhu L P and Hu Y L 2005 J. Cryst. Growth 283180

Zeng Y J, Ye Z Z, Xu W Z, Li D Y, Lu J G, Zhu L P and Zhao B H 2006 Appl. Phys. Lett. 882172743 